\title{
More of the same or marketplace of opinions? A cross-national comparison of diversity in online news reporting
}

\author{
Humprecht, Edda ; Büchel, Florin
}

\begin{abstract}
This paper examines diversity in online news reporting and explanatory factors that shape news production. The analysis is based on online news from six countries (the United States, Germany, the United Kingdom, Switzerland, France, and Italy), comparing online-only news sites and legacy media. The analysis shows that most online media reported in a diverse way, comprising multiple topics and actors. Furthermore, eventdriven news journalism explains the occurrence of high diversity in news reporting. Available resources and the intensiveness of online reporting (the extent as well as the editing style) also account for diversity. We draw from these findings to make a contribution to research on diversity in online news and to comparative communication studies. Qualitative comparative analysis is used to reflect on the direction and meaning of changes in journalistic practices in the current media environment.
\end{abstract}

DOI: https://doi.org/10.1177/1940161213497595

Posted at the Zurich Open Repository and Archive, University of Zurich

ZORA URL: https://doi.org/10.5167/uzh-86377

Journal Article

Accepted Version

Originally published at:

Humprecht, Edda; Büchel, Florin (2013). More of the same or marketplace of opinions? A cross-national comparison of diversity in online news reporting. International Journal of Press/Politics, 18(4):436-461.

DOI: https://doi.org/10.1177/1940161213497595 
--- A later version of this article was published in the International Journal of Press/Politics ---

More of the Same or Marketplace of Opinions?

\section{A Cross-National Comparison of Diversity in Online News Reporting}

Edda Humprecht and Florin Büchel

University of Zurich

Author's Note

Edda Humprecht and Florin Büchel are research and teaching associates at the Institute of Mass Communication and Media Research, University of Zurich. They both work in the division for international and comparative media research.

Correspondence concerning this paper can be sent to Edda Humprecht, Institute of Mass Communication and Media Research, University of Zurich. Andreas st. 15, 8050 Zürich, Switzerland. E-mail to e.humprecht@ipmz.uzh.ch, phone: +41 446352042. 


\begin{abstract}
This paper examines diversity in online news reporting and explanatory factors that shape news production. The analysis is based on online news from six countries (USA, Germany, UK, Switzerland, France, and Italy), comparing online-only news sites and legacy media. The analysis shows that most online media reported in a diverse way, comprising multiple topics and actors. Furthermore, event-driven news journalism explains the occurrence of high diversity in news reporting. Available resources and the intensiveness of online reporting (the extent as well as the editing style) also account for diversity. We draw from these findings to make a contribution to research on diversity in online news and to comparative communication studies. Qualitative Comparative Analysis (QCA) is used to reflect upon the direction and meaning of changes in journalistic practices in the current media environment.
\end{abstract}

Keywords: Media diversity, online journalism, news production, comparative research, QCA 
The last decade has seen a dramatic shift from print to online media in many Western countries (Downie and Schudson 2009). This trend not only implies that traditional media outlets such as established newspapers have an increasing online readership; it also points to an explosion in the number of media outlets, information sources, and news providers available. This shift towards online news dissemination raises two important questions. First, the genesis of different types of online news media has raised expectations about a growing diversity of opinion, particularly as a platform for different interests and point of views (Mutz and Young 2011). Second, established scholarship has argued that increasing media pluralism may also foster diversity in news reporting (Napoli 1999). It assumes that a high number of different available news sources may lead to a wide variety of different topics, actors, and opinions within single media outlets.

Diversity of information requires provision from a wide plurality of standpoints and perspectives, combining multiple sources from within and outside the home country (Curran 2005, 2011). The extent to which news media meet the standard of a wide-ranging 'marketplace of opinions' may depend on organizational as well as national factors (Van Cuilenburg 2007). Yet commercial pressures may result in a homogenization of content, offering a limited scope of 'more of the same'. Media outlets often react to these pressures by cutting back resources (Brüggemann et al. 2012), and this makes it more difficult to provide extensive news reporting. Therefore, it could be assumed that online news media in general provide low media diversity, as they often lack working business models. Furthermore, new online-only start-ups might perform even lower than their online competitors owned by financially established media companies because of their limited resources.

In this study we analyze diversity of actors and topics in online news media in six countries. By applying a comparative approach, we aim to identify explanatory factors for different degrees of diversity in order to get a deeper understanding of current news production online. By analyzing online news content, this paper adds a contribution to studies 
on the recent growth of online journalism, and its consequences. We examine whether the evolution of online news sites and new newsrooms has been tied to more diversity in news by looking at one specific event, in this case: the 'Occupy' movement. In addition, from a methodological point of view, this paper demonstrates the advantages and applicability of Qualitative Comparative Analysis (QCA) for journalism and communication studies.

This articles proceeds as follows. First, we discuss the crucial role played by media diversity for the functioning of democracy followed by a discussion on how the commercialization of media and emergence of online news reporting may have challenged media diversity. This part ties in closely to our deduction of possible contextual factors that might explain media diversity. In the part that follows, we provide details on our data and method of QCA. Finally, we present findings of our analysis and explore further by discussing how far they may be generalized and how wide their implications may extend.

\section{Media Diversity and Democracy}

The concept of media diversity is considered to be of crucial value and a central objective of media actors and media policy (Van Cuilenburg 2007). Media diversity refers to media content and its heterogeneity regarding one or more specified characteristics. Empirically, diversity in news reporting can be conceptualized in two different ways. While external diversity refers to the plurality of media outlets on a particular market (e.g., online or national), internal diversity means diversity (e.g., of opinions, perspectives, civil society groups) in one media product (Van Cuilenburg 2007).

From a 'marketplace of opinions' perspective, media diversity is connected with the choice of each recipient of quantity and range (Hellmann 2001). The more differing options available, the more diversity is presented to the reader. However, Van Cuilenburg (2007) differentiates between the American approach to diversity, which rather underlines the freedom of communication and the plurality of news media. In contrast, many European 
countries place emphasis on the access of citizens to pluralistic information with the intent of media giving full information on events, opinions, and groups in society. Therefore, diversity is often an important objective for European public broadcasting. These differences show that it is important to take national context factors into account when studying media diversity, e.g. by comparing cross-nationally.

Recent development in media markets like shrinking advertising revenues or lack of working business models online have led many media companies to cut costs to the bone (Picard 2010). This strategy of producing news at lowest possible costs has, according to critics, serious consequences for journalistic quality and diversity of news content (Aalberg et al., 2010; Picard 2000; Bennett 2005). Moreover, the increased competition caused by new players on the market might lead to lower financial commitment to the newsroom and lower news quality (Hollifield 2006). This assumption is supported by a study of Dutch television which suggests that while moderate competition improves diversity of TV programs, ruinous competition produces excessive sameness (Van der Wurff and Van Cuilenburg 2001).

Therefore, this study is focused on diversity in media content, as we aim to investigate the choice, i.e., the variety of topics supplied to the readers. Reasons why newsrooms can or wish to produce this high standard of journalism are found at the organizational as well as the national level. In order to provide diversity, resources might be needed, e.g., to capture or interview a broader range of actors or to investigate topics besides the mainstream. In the following, we discuss factors that lead to diversity in news.

\section{News Production: What Shapes the News?}

In this study, we aim to identify explanatory conditions that lead to diverse reporting. As previous research has shown (Benson and Hallin 2007), media systems and markets have effects on news content and therefore we take a comparative approach in order to test factors on the macro- as well as on the meso-level. We argue that diverse reporting is a way of 
reflecting the complexity of societies. Hence, we assume that certain conditions must be present to foster this kind of quality journalism, and that these can be found on different levels. On the country level, the intensity with which an event is covered in its various facets will be influenced by real world conditions and the intensity with which journalists interact with these events. Variations in national reporting styles may also reflect relevant characteristics in media system structures. On the organizational level, newsrooms need resources to produce quality journalism, and variations in these resources should translate in different diversity levels. Furthermore, not all outlets see their core business area in online journalism and only those that do will make suitable efforts to provide multifaceted and diversified coverage. Finally, political leanings of news organizations may also influence how extensive and multiperspectival they report on a controversial event, for instance in comparison to other news organizations in the same market.

\section{Organizational Factors}

Economic influences on media are widely seen as the driving force behind changes in Western media systems during the last decades (Hamilton 2005). At a macro system level, these influences might lead to a neoliberal media policy that favors the market as the best allocating system for producing and exchanging media products. At the organizational mesolevel, economic influences are seen as the main reason behind media organizations' changing priorities, so that financial concerns such as profit goals and cost considerations have become powerful influences on norms and practices in news production.

Commercialization of news and a possible decrease of journalistic standards is not a new phenomenon (Picard 2011). However, this development has dipped to a new level due to technological changes linked to the rise of the Internet during recent decades. This has had massive consequences for news reporting across the globe. On the one hand, many traditional media organizations are threatened by digitalization and the search for sustainable business models to finance journalism (Picard 2011). Yet, on the other hand, new journalistic start-ups, 
so-called pure players, have emerged (Sirkkunen and Cook 2012). Several reasons explain this development, which might differ somehow in every country. As Bruno and Nielsen (2011) have shown in their in-depth report on performance of journalistic start-ups in three countries, these new outlets have often emerged because working conditions in traditional media organizations were no longer satisfactory for journalists. In this account, some journalists were innovative and created opportunities to practice their profession along the way. But these young journalistic start-ups are facing challenges, as the authors highlight. The market for online news media is dominated by legacy media organizations with existing resources at their disposal and well-known brands. On the other hand, the market for online advertising is dominated by players like Google, Yahoo, Microsoft, and Facebook. The latter also challenges legacy media, as they must not only finance their online activities — which is still difficult — but also deal with decreasing revenues from their offline media products. This rising competition on the media market thus challenges news production of most kinds of media outlets. For this reason it can be assumed that products of online-only outlets and legacy online media differ; for example, they often lack the same amount of resources, or financial pressures lead to an orientation towards mainstream topics within traditional media outlets. Furthermore, legacy media in many countries have slowly entered the online market, and their performance offline and online still differ (Benson 2010), which may be visible in the extent and form of their coverage. Beyond the organization type, scholars found that the political leaning of individual news outlets shape their news production (e.g., Besley and Prat 2006; Baron 2006; Durante and Knight 2011). Especially the reporting on social movements may be explained by media bias and national factors, like political parallelism (Kriesi 2008). Hence, we assume that newsroom affiliations partly affect how extensive and diverse media outlets cover social movements relative to their national competitors.

\section{National Factors}


We also assume that the specific shape of news reporting is not only determined by the organization-specific context. Despite the massive increase in global news flows facilitated by the growth in online journalism (but also by satellite television), differences across media systems in respect to the form and content of news reporting continue to be significant (Quandt 2008). Furthermore, news reporting is often tied to national characteristics (Esser \& Hanitzsch 2012) and those seem to persist even in a globalized online environment (Benson et al., 2010). Hallin and Mancini (2004) have shown that political and media system conditions vary between different countries and that dimensions like the development of the press market, state intervention, political parallelism or journalistic professionalization are useful to explain variations in news reporting. Kriesi (2008) argued that media systems should be taken into account when studying social movements because national structures have strong implications on their development. News reporting, for instance, can not only increase the visibility and success of social movements but also deconstruct them, for instance by focusing on a few leader figures instead of the movement itself. Moreover, strong political parallelism and journalistic professionalization may also lead to differences in news reporting. Thus, these national context factors constitute the starting point of our research and serve as dimensions of comparison. When studying news coverage on a certain issue, like the 'Occupy Wall Street' social movement, one has to take into account the national relevance of this event. The movement protested against growing social and economic inequality and the growing influence of the financial service sector. It links these problems to the current global financial crisis. The protests began in September 2011 in New York City and spread to many countries around the world. Naturally the protests had more participants in countries where economic and social problems were more urgent, which might have led news media to more extensive news coverage. Regarding the coverage of social movements, scholars have pointed in particular to the relevance of event-driven news (Bennett and Livingstone 2003). It treats news as contingents on country characteristics and as a function of the event environment 
(Peter 2003). Event-driven news focuses on practices that are directly related to the interaction between journalists and events and results from national occurrences and unexpected incidents. Bennett and Livingstone distinguish between event-driven, initially initiated and reporter initiated news. We therefore assume that in countries where the 'Occupy Movement' played an important role, news outlets covered the event more intense and more diverse. In this case the described national relevance of the event might be mainly dependent on a) the amount of public participation in the movement, and b) the financial situation of the national economy.

\section{Explanatory Conditions and Research Questions}

Research on media and content production, comparative and otherwise, has often been conducted at the individual level and has not taken into account the larger structure in which journalists operate. Shoemaker and Reese (1996) therefore proposed a "hierarchy of influences" at different levels (individual level, routines level, organizational level, and extramedia level) in order to monitor context factors at different levels that shape news production. Hence we focus on context conditions within various dimensions to compare content from online sites of legacy media and journalistic start-ups. Against the discussed theoretical background, those conditions — amongst others — are assumed to be crucial in content production of online news media. We therefore assume a positive relationship between internal media diversity and:

(1) The national relevance of the topic: We assume that the extent of public participation in the 'Occupy' protests or general national economic situation lead to eventdriven reporting.

(2) The resources available at the organizational level: The number of journalists in a newsroom is supposed to have an important impact on the extensiveness of the coverage.

(3) The orientation towards high-quality online news reporting: We assume the usage of online-specific editing tools, like hypertextual editing, to be indicative of an orientation 
towards quality reporting on the meso-level, as it reflects a more ambitious journalistic approach than just posting 'print-like' articles on their web sites.

(4) The extent of online reporting: The length of single articles is taken into account, because longer article are more likely to feature multiple views and aspects.

In short, we argue that differences in news reporting are not only a result of political leanings but also of the organizational setup. All else equal, this setup differs substantially between established media outlets and newly founded Internet-based start-ups. Specifically, we assume that one of the major consequences of the massive increase in online news reporting has led to a substantial expansion in external media diversity. News media outlets like The Huffington Post in the U.S. or Rue 89 in France have gained a wide readership and importance as opinion leaders in their countries and become serious competitors of existing legacy media (Bruno and Nielsen 2011). Furthermore, at an organizational level, available resources and professionalization (e.g., orientation towards online journalism) and eventdriven reporting are important for selecting and editing news topics. These conditions serve as external framing conditions and affect how journalists define new situations and how they select and frame news events and topics (Esser and Strömbäck 2012). In particular it affects their level of multiperspectival reporting. Relationships between the macro- and meso-level variables discussed above are visualized in figure 1:

[Figure 1 here]

To address whether differences in content exist, exploratory research questions were formulated rather than hypotheses. Our explanatory analysis should be seen as a way to generate hypotheses. The previous research on actor and topic diversity in different types of online news media is too sparse to formulate hypotheses. Our two research questions read as follows: 
More of the Same or Marketplace of Opinions?

RQ1: Do different news outlets show a varying amount of diversity in news reporting?

RQ2: Which constellations of organizational and national conditions are most conducive for high diversity (of topics and actors) in news media content?

\section{Data and Method}

\section{Method of Analysis}

The main data-analysis strategy used in this study is the QCA method. It is a wellestablished technique in political science (e.g., Bochsler 2011; Samford 2010; Braumoeller and Goertz 2000) and slowly entering into the field of media and communication studies (see Brüggemann and Kleinen-von Königslöw 2013, Nguyen Vu 2010, Downey and Stanyer 2010). The main reasons for using QCA in this case are: (1) the medium-sized sample of news outlets (because internal media diversity can only be measured by analyzing content per outlet); (2) the set-theoretic arrangement of the study and the research questions; and (3) the ability to easily identify very complex interactions (combinations) of conditions, which is highly complicated, using other methods such as multilevel-regression when you want to model three-way and higher interactions. QCA is a sophisticated extension of the most different and most similar design logic and was developed by Charles Ragin (2008). It combines quantitative, variable-based logic and qualitative, case-based interpretation. It assumes that (a) causality is a combination of various (national and systems) conditions (explanatory variables) that eventually produces a news outcome; (b) several different combinations of organizational and systems conditions may produce the same outcome in news performance; and (c) depending on the context a given condition may have a different impact on the outcome. Thus different causal paths - each path being relevant, in a distinct way - may lead to the same outcome (high or low diversity of actors and topics). With QCA, we could analyze and interpret data even if the outcome results from several various combinations of the causal conditions, since QCA allows for examining a variety of political 
and media conditions and the interaction of these conditions (rather than seeking to isolate the discreet effects of independent variables). In a two-step approach, we first identified conditions at the national level that were sufficient for the outcome (for advantages of this approach, see Schneider and Wagemann 2012) and used this solution as a condition in the second step of the analysis to identify interactions between macro- and meso-conditions. Compared to other methods like cluster analysis, QCA allows the researcher to study differences and commonalities between cases in greater detail (since it employs a caseoriented interpretation). QCA is based on set theory, and therefore codes all cases as being either absent or present according to their variable values. Normally a high value indicates the presence of a certain variable, while a low value means its absence. The cut-off point on the scale which divides the absent and present cases has to be set by the researcher, based on theoretical case knowledge. This procedure is called "calibration" and can be seen as one of the major strengths of QCA as qualitative knowledge and quantitative data are combined within this step. In a combination of our theoretical knowledge and the data at hand we defined the cross-over point which devides cases showing the outcome and not showing the outcome.In the following, we test if the conditions or combinations of these conditions mentioned above constitute the outcome, diversity in news content.

\section{Sample}

The sampling procedure was conducted in three steps. First, we selected six countries with varying relevance of the 'Occupy' movement due to the degree of participation and economic pressures (national debt and unemployment rate). This variation was important, because we assumed this to create event-driven reporting. Furthermore, journalists in those countries might have a higher interest in informing the public about these events and therefore report more diverse and balanced stories about them. For the sake of validating national findings, we took a comparative approach and chose two countries from each of the three media systems types described by Hallin and Mancini (2004). We then selected the two most- 
used online news sites from newspapers and online-only outlets, four outlets per country and 24 in total (see table 1). These sites were preferred to radio and television news websites, because online newspapers are greater in number and geographical diversity. As online-only newspapers have not evolved in all countries, we selected two online off-sets of established media brands which have an independent newsroom. In those two cases (Spiegel Online and The Telegraph), we assumed that resources are tied to the newsroom and subsidiaries within one media trust act independently. ${ }^{\mathrm{i}}$ Finally, we took a two-month period (the beginning of the 'Occupy' movement on September 17 to November 17, 2011) and selected the 40 most important articles of each news outlet, using the 'Google relevance' function for news search.

[Table 1 here]

\section{Measurement}

The analysis was based on a large-scale quantitative content analysis of articles from daily newspapers sites and online-only news sites. Some 25 trained, mostly native-speaking coders coded up to 40 articles per news site $(\mathrm{N}=759)$. After the coder training, we conducted two reliability tests, and the second one showed satisfying results with a percentage agreement of .76 for category 'topics' and .9 for category 'actors'. ii From around 30 variables coded, the variables 'actors' and 'topics' were used to calculate the outcome of this study, since news diversity has two dimensions within this study: actor diversity and topic diversity. Diversity is measured using the diversity index. As McDonald and Dimmick (2003) have shown in their examination of diversity measures, the diversity index is adequate to measure diversity on two dimensions: it reflects categories of classification and distribution of elements within those categories. The diversity index denotes the relative frequency of one given category within the mix and the number of categories given. It is standardized so that its values vary between 0 and 1 . High diversity close to 1 implies that many or all types of news 
are equally presented in the mix, and values close to 0 indicate low diversity (e.g., when all stories belong to one category). This way of measuring content diversity shows if several viewpoints of actors and topics are mentioned in one article (for additional information on quantities of topics and actors in single countries, see appendix tables A I and A II).

In order to analyze the performance of different news sites, we selected a specific event rather than routine coverage. This event had to be internationally relevant, so that news outlets in all countries would at least potentially cover it. Furthermore, it was important that the event was controversial in order to assure data variance. The social movement 'Occupy Wall Street' fitted all these criteria: demonstrations took place in different countries, and it was a widespread topic in the media. Additionally, it is a controversial movement that initiated discussions, and prominent voices both supporting and dismissing the movement were raised quickly. In terms of diversity regarding actors and topics, a focus solely on the movement (support) or a focus only on actions of authorities (disregard) would score low on the diversity index.

For the data collection concerning the explaining conditions, we proceeded in three steps. First, we collected data for the country-level variables 'national debt' in percentages of the respective GDP (sources: Eurostat; U.S. Department of the Treasury; and for Switzerland SECO, all 2009), the 'unemployment rate' (sources: Eurostat; SECO for Switzerland; U.S. Bureau of Labor Statistics, all 2011) and the 'number of protesters' (source: Guardian data blog 2012) on one given day (October 15, when the protest intensity peaked in most countries). The number of protesters was weighted by the inhabitants of each country. We combined the data on national debt and unemployment rate into one indicator for the amount of economic crisis in each country using the mean of the two sources. Second, we collected data for the organization-level variables. We took the percentage of articles with more than 500 words per news outlet as an indicator of the 'extensive coverage' condition and the percentage of articles that use hyperlinks per news site as an indicator for 'hypertextual 
editing'. These data stem from our content analysis and were coded dichotomous. We found the 'number of journalists' for each news outlet (as an indicator for the newsroom size and amount of resources) on the homepages or in company reports. ${ }^{\text {iii }}$

Table 2 gives an overview over data at the macro and meso-level:

[Table 2 here]

Finally, we had to calibrate continuous conditions into so-called fuzzy sets (see Table 3). The calibration of the data took into account the full range of possible values as well as our theoretical and empirical knowledge of our cases. The cross-over point for the outcome was set at 0.86 as this value demarks the clearest break between the different news outlets in the continuum of diverse coverage. The calibration algorithm provided by Ragin (2008) included in the software FSQCA 2.0 was used to determine the concrete translation of data into calibrated values. This step allows organizing data in sets where each element has a certain value. We then tested whether any explanatory factors or combinations thereof explain diversity in news content.

[Table 3 here]

\section{Findings}

The diversity values of news outlets in our sample varied between .7 (news.ch) and .95 (repubblica.it). News.ch is an outlier, and all other cases range between .82 and .95 . The diversity index measured the degree to which individual news outlets reported about the Occupy Movement by discussing a broad range of different actors and subtopics (see table A I and A II). These relatively high values indicate that all tested news providers provide diverse reporting on the Occupy movement to a certain extent. However, a small but significant gap 
appears between the cases Corriere della Sera and NY Times, which therefore has been chosen as the crossover point.

[Figure 2 here]

We aimed in this study to identify combinations of sufficient and necessary conditions to explain which constellations of organizational and national conditions are most conducive for high diversity of topics and actors in news media content. To do so, we applied a two-step analysis: in the first step, we found that out of all tested macro conditions, the amount of national debt and the unemployment rate or the number of protesters from all tested possible macro conditions, were crucial to produce the outcome. This solution regarding national context factors was then combined into a single indicator, which was finally used as a further condition in the second step of the analysis. In this second step, we additionally found that the size of newsroom, the length of each article, and the use of hypertextual editing explained the outcome of high diversity. However, the actual interactions between macro- and meso-level indicators have to be considered to investigate why different news outlets covered the 'Occupy' movement in a diverse way; we found three different combinations of conditions leading to the outcome of high diversity: ${ }^{\text {iv }}$

1. News sites from countries with high national relevance (event-driven reporting, activated by high national debt, high unemployment rate, or high number of protestors) and a small newsroom;

2. News sites from countries with event-driven reporting and online orientation of the newsroom (hypertextual editing);

3. News sites from countries with low national relevance of the topic that produced extensive coverage. 
The first combination consisted of the Italian online-only news sites Linkiesta, Lettera43, the French Rue89 and Slate, the German Telepolis and two newspaper sites SZ (online site of the German Süddeutsche Zeitung), and the Italian Repubblica. These news outlets, coming from countries where Occupy protests played an important role, have small online newsrooms but nevertheless managed to report about the event in a diverse way. As we assumed that the number of resources is an important factor for diverse news reporting, we can expect those sites as being especially interested in the topic.

The second combination explained mostly online-only sites, as holds true for Linkiesta, Lettera43, Rue89, Slate, Telepolis, Huffington Post, Politico, and SPON. In addition, the newspaper sites New York Times, SZ, and Le Monde could be explained. The latter were supposed to share a certain affinity for the 'Occupy' movement, as it was a civil movement that questioned elites and capitalism, which appeared to suit their editorial line. Furthermore, these outlets fostered online journalism by using hypertextual editing.

The last combination described the cases Guardian, times.co.uk, and the online-only sites Open Democracy, Journal 21, and $N e w s^{\mathrm{v}}$. These British and Swiss news sites have not produced event-driven news, as their countries were little affected by the 'Occupy' protests but nevertheless reported on the topic extensively. 'Pure players' are assumed to report on the topic because the mainstream media did not and therefore left a gap for them to fill. The political leaning might also be the reason why The Guardian, which has a labourist readership (Ipsos MORI 2010), reported extensively and diversely about the event. Whereas The Times, which introduced a pay-wall on its website was not mainly interested in multiplying site visits but in long-term reader retention, eventually made the effort to report diverse on the social movement. The solution plot and constellations of conditions are shown in figure 3:

[Figure 3 here] 
One advantage of QCA is that it allows control of the negated outcome - in this case, the absence of high diversity in news. We tested it, and our findings showed that our conditions also explain these cases. The analysis carried out two solution terms:

1. The Swiss newspaper sites $N Z Z$ and $T A$ as well as the British Telegraph failed to report in a diverse manner, because the national relevance of the topic was rather low in their countries.

2. Le Figaro, Corriere della Sera, LA Times, and FAZ failed to report in a diverse manner, despite having a national relevance of the Occupy movement. These corporate newspaper sites have not yet adapted their quality journalism to the web, as they remained static and print-like in their editing style rather than using hypertexts or linking additional sources - despite having large newsrooms available. We have not analyzed the coverage of the corresponding print sections within this study, but it could be assumed that they published more extensive articles offline.

[Figure 4 here]

These findings logically support our results of high diversity, because the absence of the 'high diversity' outcome could be explained by using the same conditions. Therefore it seems plausible to state that our chosen conditions play an important role in production of diverse news content.

\section{Conclusion}

Before we summarize our main results and draw further conclusions, it seems in order to emphasize that our analysis was only able to include a limited set of exemplary variables. Hence we cannot claim that our chosen indicators are able to comprehensively measure all aspects of content diversity. The fact that we coded only three actors and topics at a time may 
have further limited the study's explanatory power. We would also like to point out that we have not measured the amount or type of different opinions or ideological diversity, as one might do with framing analysis. We thus hope that future studies analyze the content more extensively, study ideological viewpoints and add further explaining conditions. However, such limitations are not unusual for empirical research that attempts to explore new territory (as we did with QCA; see below).

Within these constraints, our study demonstrates that online news media reported multi-perspectively on the Occupy movement, scoring between .7 and .95 on the applied diversity index. These results indicate that under certain conditions online media can provide a 'marketplace of opinions' and that this way of reporting does not depend on a certain media genre (e.g., print vs. online). Comparing online-only and legacy news sites, our results further indicate that online-only sites produce more aspects of diversity in their Occupy coverage. However, legacy media with a focus on online reporting also scored high on the applied diversity index. Yet legacy media which have set their priorities to a lesser amount on online reporting performed rather low. Both groups are located in countries where the high relevance of the Occupy theme led us to expect high levels of event-driven news, but even here the more diverse reporting style (e.g., utilizing hypertextual editing) came from online-oriented outlets.

The study has also shown that larger online news outlets differ from smaller ones and that such differences also exist between online-only outlets and legacy newspaper sites. Our results indicate that almost all online-only sites and those from Internet-savvy news outlets broader set of actors and topics in their coverage. Combinations of different conditions at the macro as well meso level were able to explain this outcome (and moreover its negation). This is important, because it underpins the assumption that news performance is closely linked to organizational and editorial factors. 
According to our analysis, the extent to which news media meet the standard of a wide-ranging 'marketplace of opinions' by representing institutionalized and noninstitutional, non-elite sources and representing news from multiple societal domains depends on various contextual factors including (1) national or regional relevance of a given topic (economic situation or amount of public participation in protest), (2) resources available (editorial staff), (3) extent of coverage, and (4) online orientation (hypertextual editing). Current economic challenges for the media industry - and especially of online news outlets seem to be related to the provision of news diversity. These economic pressures might also explain the fact that news outlets with a presumed conservative readership like The Telegraph (Ipsos MORI 2010) have not afforded much time and space on the controversial Occupy movement. Since we have not analyzed the diversity of opinions or ideologies we cannot decide whether the fact that coverage included different actors and topics also indicates different viewpoints. Nevertheless, we assume that this way of reporting creates a more differentiated picture of the Occupy issue.

What future developments can be expected? Commercial pressures may result in homogenization of content, offering a limited scope of 'more of the same'. Many media companies fight their economic problems via cost-cutting, and this often leads to shrinking resources and staffing levels (Brüggemann et al. 2012). This results in fewer journalists being able to cover the daily news flow, and less time for longer, more diverse articles. Besides, economic problems and the recession's impact on the advertising market have led some legacy media to down-size their reporting. In response, online-only start-ups have become influential in some countries under the banner of investigative reporting by fulfilling a critical monitoring role that existing media organizations had left open (Chalaby 2004; Curran 2011; Downie and Schudson 2009). As our findings indicate, these media outlets are often capable of adding elements of diversity to their articles. Furthermore, legacy media that have invested in their online newsrooms are also championing high diversity, and thus succeeded in 
transferring high news performance from print to online. On the one hand, the changing business priorities of journalism have been perceived as a threat to news media. On the other hand, they have also given democracy a chance. In countries where legacy media were no longer able (or willing) to provide a multi-faceted representation of society, new players emerged that filled the gap. This may urge traditional outlets to rethink their approach to news reporting.

Future research is needed to explore whether our findings regarding the Occupy coverage also applies to routine coverage not anchored in such a specific set of events. However, on a more abstract level, our findings may be generalizable beyond our sample of countries to the extent that news media in many Western countries face similar challenges and new journalistic start-ups have arisen in many news environments. Very often they pay more attention to developments like social movements, because they explicitly aim for diversity of opinions and the representation of non-elite audiences (Sirkkunen and Cool 2012).

Interestingly, in countries where legacy news media are still doing relatively well and have a broad audience (as in Germany or Switzerland), new start-ups can hardly achieve the acceptance of media users. Either they have a very small reach and very limited resources, or - in the case of Spiegel Online - are independent subsidiaries of established media brands.

In terms of methodological approaches, our paper also demonstrates the advantages of using QCA in the field of journalism and communication studies. For the analysis of news performance on different levels, as Shoemaker and Reese (1996) proposed, QCA offers an elegant strategy to link context factors at the meso- and macro-level to content data and to analyze their complex interactions. The set theoretic arrangement best suits interpretation and explanation of constellations under varying conditions that lead to internal diversity. The combination of quantitative data and in-depth case knowledge provides a suitable starting position to analyze the complex interplay between economic, organizational, and editorial explanatory factors that shape online news content. QCA has shown the relative importance 
of variables such as the role of editorial resources and online orientation. These variables cannot be regarded independently but have to be modeled as mutually dependent in order to explain the outcome. For example, media outlets that aim to increase their online news performance might not only use hyper-textual editing but also increase their resources by employing more journalists.

Our paper aimed to demonstrate that content analysis combined with structural conditions can explain variations in diversity of event driven news (here in response to the 'Occupy Wall Street' movement). It aims to contribute to research on news performance and may help us to understand processes of external media diversification and how it is tied to internal media diversity in online news reporting. We invite scholars to pursue this route further with larger-scale research designs. 
More of the Same or Marketplace of Opinions?

\title{
Endnotes
}

\begin{abstract}
${ }^{i}$ Some other selected online-only media outlets, e.g. Huffington Post, are also well-established or belong to big companies, therefore we assume them to equal in terms of access to resources. Furthermore, telegraph.co.uk was assumed to be the best functional equivalent of Spiegel Online.

ii As we achieved high agreements between all coders for the categories topics and actors, we used Holsti's percentage agreement to calculate the reliability values for these categories. Reliability indicators like Krippendorff's alpha or Cohen's kappa are too conservative when values are expected to occur by chance, which may be the case for very high agreements (Lombard et al. 2002). Nevertheless, scholars argued that high agreements can also be an indicator for high reliability and recommend using more liberal indicators like percentage agreements (Gwet 2001.).

${ }^{i i i}$ Usually it was possible to discern between journalists working for the online versus those working for the respective offline outlets. If not, we assumed them to work for both newsrooms.

${ }^{i v}$ The obligatory test on necessary conditions showed that none of the single conditions has necessity consistency higher than .75 .
\end{abstract}

${ }^{v}$ The solution consisted of one true contradiction, News.ch. We accepted this because of the small sample of articles for this case (see Table 1). 


\section{References}

Aalberg, T., P. van Aelst and J. Curran 2010. "Media Systems and the Political Information Environment: A Cross-National Comparison.” In: The International Journal of Press/Politics $15: 255-271$.

Baron, D. P. 2006. "Persistent Media Bias.” Journal of Public Economics, 90(1-2), 1-36.

Besley, T. and A. Prat (2006). "Handcuffs for the Grabbing Hand? Media Capture and Government Accountability.” American Economic Review, 96(3), 720-736.

Bennett, W. L. 2005. News - The Politics of Illusion (6 ed.). New York, NY: Pearson Longman.

Benson, R., M. Oersten, M. Powers, I. Willig and S. Vera. (2010). "Media systems online and off: Comparing the Form of News in the U.S., Denmark, and France." Journal of Communication, 62(2012):21-38. .

Benson, R. and D. Hallin 2007. "How States, Markets and Globalization Shape the News: The French and US National Press, 1965-97. European Journal of Communication, 22(1): 27-48.

Bochsler, D. 2011. "It is not how many Votes you get, but also where you get them. Territorial Determinants and Institutional Hurdles for the Success of Ethnic Minority Parties in PostCommunist Countries.”Acta Politica 64(2): 217-238.

Boczkowski, P. and M. de Santos 2007. "When more Media Equals Less News: Patters of Content Homogenization in Argentina's Leading Print and Online Newspapers." Political Communication (24):167-180.

Boczkowski, P. 2004. "The process of adopting multimedia and interactivity in three online newsrooms." Journal of Communication 54(2):197-213.

Braumoeller, B. and G. Goertz 2009. "The Methodology of Necessary Conditions.” American Journal of Political Science, 44(4): 844-858.

Brüggemann, M., and K. Kleinen-v. Königslöw 2013: "Cosmopolitan Coverage: Causal Recipes for Patterns of Foreign News Coverage in European Newspapers.” European Journal of Communication 28(4).

Brüggemann, M., F. Esser and E. Humprecht 2012. "The Strategic Repertoire of Publishers in the Media Crisis.” Journalism Studies DOI:10.1080/1461670X.2012.664336.

Bruno, N. and R. Nielsen 2011. Survival is Success: Journalistic Online Start-Ups in Western Europe. Oxford: The Reuters Institute for the Study of Journalism.

Carpenter, S. 2008. "Source Diversity in U.S. Online Citizen and Online Newspaper Articles." Paper presented at the 8th International Symposium on Online Journalism, Austin, TX.

Cassidy, W. 2005. "Variations on a theme? The professional role conceptions of print and online newspaper journalists.” Journalism and Mass Communication Quarterly 82: 264-280. 
Chalaby, J. 2004.”Scandal and Rise of Investigative Reporting in France.” American Behavioral Scientist 47:1194-1207.

Curran, J. 2011. Media and Democracy. London: Routledge.

Curran, J. 2005. "What Democracy Requires of the Media." In The Institutions of American Democracy: The Press, ed. G. Overholser and K. Jamieson. Oxford: Oxford University Press, pp. 120-140.

Downey, J. and J. Stanyer 2010. "Comparative media analysis: Why some fuzzy thinking might help. Applying fuzzy set qualitative comparative analysis to the personalization of mediated political communication." European Journal of Communication 25: 331-347.

Durante, R. and B. Knight 2012. Partisan control, media bias, and viewer responses: evidence from Berlusconi's Italy. Journal of the European Economic Association, 10: 451-481. doi: $10.1111 / \mathrm{j} .1542-4774.2011 .01060 . \mathrm{x}$

Downie, L. and M. Schudson 2009. The Reconstruction of American Journalism. New York: Columbia Journalism Review.

Esser, F. and T. Hanitzsch 2012. "On the Why and How of Comparative Inquiry in Communication Studies." In The Handbook of Comparative Communication Research, ed. F. Esser and T. Hanitzsch. New York: Routledge.

Esser, F. and J. Strömbäck 2012. "Comparing News on National Elections.” In The Handbook of Comparative Communication Research, ed. F. Esser and T. Hanitzsch. New York: Routledge.

Freedman, D. 2010. “The Political Economy of the 'Net' News Environment". In: New Media, Old News -. Journalism \& Democracy in the Digital Age., ed. N. Fenton. London: Sage.

Galtung, J. and M. Ruge 1965. "The structure of foreign news: the presentation of the Congo, Cuba and Cyprus crises in four Norwegian newspapers.” Journal of International Peace Research, 1: 64 91.

Guardian data blog 2012. Link: http://www.guardian.co.uk/news/datablog/2011/oct/17/occupyprotests-world-list-map?newsfeed=true (checked 24/07/12).

Gwet, K. 2001. Handbook of Inter-Rater Reliability. Gaithersburg: StatAxis Publishing.

Hamilton, J. 2004. All the news that's fit to sell: How the market transforms information into news. Princeton, N.J.: Princeton University Press.

Hellmann, H. 2001. "Diversity - An End in Itself? Developing a Multi-Measure Methodology of Television Programme Variety Studies.” European Journal of Communication, 16: 181-208.

Ipsos MORI. 2010. “Voting by Newspaper Readership 1992-2010.” Link: http://www.ipsosmori.com/researchpublications/researcharchive/poll.aspx?oItemId=2476\&view=wide.

Kriesi, H. 2008. “Social Movements”. In: Comparative Politics, ed. D. Caramani. Oxford: University Press. 
Lombard, M., J. Snyder-Duch and C. Bracken 2002. "Content Analysis in Mass Communication: Assessment and Reporting of Intercoder Reliability." Human Communication Research 28(4): 587-604.

McDonald, D. and J. Dimmick 2003. "The Conceptualization and Measurement of Diversity." Communication Research 30:60-79.

McQuail, D. 2000. Mass Communication Theory. London: Sage.

McQuail, D. and J. Van Cuilenberg 1983. "Diversity as a media policy goal: A strategy for evaluative research and a Netherlands case study." Gazette, 31(3):145-162.

Mutz, D. and L. Young. 2011. "Communication and Public Opinion." Public Opinion Quarterly 75(5):1018-1044.

Napoli, P. 1999. "Deconstructing the Diversity Principle.” Journal of Communication 49(4):7-34.

Nguyen Vu, H. 2010. Money Matters - A Cross-National Study of Economic Influences on TV News. Doctoral thesis at the University of Zurich, http://opac.nebis.ch/ediss/20100925_003287877.pdf.

Peter, J. 2003. "Country Characteristics as Contingent Conditions of Agenda Setting: The Moderating Influence of Polarized Elite Opinion." Communication Research 30(6):683-712.

Picard, R. 2011. Mapping Digital Media: Digitalization and Media Business Models. Open Society Media Program, Cambridge: Open Society Foundation.

Picard, R. 2010. Value Creation and the Future of News Organizations: Why and How Journalism Must Change to Remain Relevant in the Twenty-First Century. Lisbon: Media XXI.

Picard, R. 2000. "Audience Fragmentation and Structural Limits on Media Innovation and Diversity." In Media \& Open Societies: Cultural, Economic ad Politcy Foundations fpr Media Openness and Diversity in East and West, ed. J. Van Cuilenburg and R. van der Wurff. Amsterdam: Het Spinhuis.

Quandt, T. 2008. "News on the World Wide Web.” Journalism Studies 9(5):717-738.

Ragin, C. 2008. Redesigning Social Inquiry. Fuzzy Sets and beyond. Chicago: University of Chicago Press.

Samford, S. 2010. "Reform in Latin America - Averting 'Disruption and Reversal': Reassessing the Logic of Rapid Trade.” Politics \& Society, 38:373-407.

Schneider, C and C. Wagemann 2006. "Reducing complexity in Qualitative Comparative Analysis (QCA): Remote and proximate factors and the consolidation of democracy." European Journal of Political Research 45:751-786.

Schneider, C. and C. Wagemann 2012. Set-Theoretic Methods in the Social Sciences: A Guide to Qualitative Comparative Analysis. Cambridge: Cambridge University Press. 
Schulz, W. 1976. Die Konstruktion von Realität in den Nachrichtenmedien. Freiburg and Munich: Verlag Karl Alber.

Shoemaker, P. and S. Reese 1996. Mediating the message: Theories of influences on mass media content. 2nd Edition. White Plains, N.Y.: Longman.

Sirkkunen, E. and Cool, C. 2012. "Chasing Sustainability on the Net. International research on 69 journalistic pure players and their business models." Tampere, Finland: Juvenes.

Van Cuilenburg, J. 2007. "Media Diversity, Competition and Concentration: Concepts and Theories". In: Media between Culture and Commerce, eds. E. de Bens et al. Chicago: The University of Chicago Press

WAN 2010. World Press Trends. Paris: World Association of News Papers.

Van der Wurff, R., and J. van Cuilenburg 2001. "Impact of moderate and ruinous competition on diversity: the Dutch television market." Journal of Media Economics, 14(4), 213-229. 


\section{Tables}

Table 1: Sample of Online News Outlets

\begin{tabular}{|c|c|c|c|c|}
\hline Country & Media Type & URL & Abbreviation (as used here) & $\mathbf{n}$ \\
\hline \multirow{4}{*}{ Switzerland } & \multirow[t]{2}{*}{ Newspapers } & nzz.ch & NZZ & 36 \\
\hline & & tagesanzeiger.ch & TA & 39 \\
\hline & \multirow[t]{2}{*}{ Pure Player } & journal21.ch & Journal 21 & 6 \\
\hline & & news.ch & News & 17 \\
\hline \multirow{4}{*}{ Germany } & \multirow[t]{2}{*}{ Newspapers } & sueddeutsche.de & $\mathrm{SZ}$ & 33 \\
\hline & & faz.net & FAZ & 25 \\
\hline & \multirow[t]{2}{*}{ Pure Player } & spiegel.de & SPON & 39 \\
\hline & & telepolis.de & Telepolis & 22 \\
\hline \multirow{4}{*}{ France } & \multirow[t]{2}{*}{ Newspapers } & lemonde.fr & Le Monde & 38 \\
\hline & & lefigaro.fr & Le Figaro & 40 \\
\hline & \multirow[t]{2}{*}{ Pure Player } & rue89.com & Rue89 & 17 \\
\hline & & slate.fr & Slate & 18 \\
\hline \multirow{4}{*}{ Great Britain } & \multirow[t]{2}{*}{ Newspapers } & guardian.co.uk & Guardian & 40 \\
\hline & & times.co.uk & Times & 33 \\
\hline & \multirow[t]{2}{*}{ Pure Player } & opendemocracy.net & Open Democracy & 34 \\
\hline & & telegraph.co.uk & Telegraph & 37 \\
\hline \multirow{4}{*}{ Italy } & \multirow[t]{2}{*}{ Newspapers } & repubblica.it & Repubblica & 33 \\
\hline & & corriere.it & Corriere della Sera & 40 \\
\hline & \multirow[t]{2}{*}{ Pure Player } & linkiesta.it & Linkiesta & 24 \\
\hline & & lettera43.it & Lettera43 & 29 \\
\hline \multirow{4}{*}{ United States } & \multirow[t]{2}{*}{ Newspapers } & nytimes.com & NY Times & 40 \\
\hline & & latimes.com & LA Times & 39 \\
\hline & \multirow[t]{2}{*}{ Pure Player } & huffingtonpost.com & Huffington Post & 40 \\
\hline & & politico.com & Politico & 40 \\
\hline
\end{tabular}


Table 2: Original data on macro- and micro-levels

\begin{tabular}{|c|c|c|c|c|c|c|c|}
\hline Country & Site & $\begin{array}{l}\text { yment } \\
\text { national }\end{array}$ & $\begin{array}{l}\text { Intensity of } \\
\text { protests } \\
\text { (weighted, } \\
\text { \%) }\end{array}$ & $\begin{array}{l}\text { Articles } \\
\text { with more } \\
\text { than } 500 \\
\text { words, \% } \\
\end{array}$ & $\begin{array}{l}\mathrm{N}^{\circ} \text { of } \\
\text { journalists }\end{array}$ & $\begin{array}{l}\text { Articles } \\
\text { with } \\
\text { hyperlinks, } \\
\%\end{array}$ & $\begin{array}{l}\text { Outcome: } \\
\text { diversity inc } \\
\text { topics and } \\
\text { actors } \\
\end{array}$ \\
\hline \multirow{4}{*}{$\mathbf{C H}$} & $\mathbf{N Z Z}$ & 21.1 & 0.0250 & 8.3 & 198 & 52.8 & 0.83 \\
\hline & TA & 21.1 & 0.0250 & 25.6 & 63 & 12.8 & 0.83 \\
\hline & Journal21 & 21.1 & 0.0250 & 83.3 & 5 & 0.0 & 0.87 \\
\hline & news.ch & 21.1 & 0.0250 & 64.7 & 24 & 0.0 & 0.70 \\
\hline \multirow{4}{*}{ D } & SZ & 40.15 & 0.0439 & 60.6 & 28 & 90.9 & 0.87 \\
\hline & FAZ & 40.15 & 0.0439 & 64 & 360 & 0.0 & 0.83 \\
\hline & SPON & 40.15 & 0.0439 & 41 & 176 & 87.2 & 0.87 \\
\hline & Telepolis & 40.15 & 0.0439 & 36.4 & 22 & 100.0 & 0.88 \\
\hline \multirow{4}{*}{$\mathbf{F}$} & Le Monde & 44.35 & 0.0063 & 26.3 & 170 & 57.9 & 0.89 \\
\hline & Le Figaro & 44.35 & 0.0063 & 27.5 & 300 & 35.0 & 0.84 \\
\hline & Rue89 & 44.35 & 0.0063 & 58.8 & 22 & 88.2 & 0.91 \\
\hline & slate.fr & 44.35 & 0.0063 & 50 & 20 & 100.0 & 0.91 \\
\hline \multirow{4}{*}{ UK } & Guardian & 38.85 & 0.0119 & 85 & 800 & 40.0 & 0.87 \\
\hline & Times & 38.85 & 0.0119 & 45.5 & 400 & 0.0 & 0.88 \\
\hline & Open Democracy & 38.85 & 0.0119 & 100 & 25 & 85.3 & 0.89 \\
\hline & Telegraph & 38.85 & 0.0119 & 43.2 & 510 & 16.2 & 0.82 \\
\hline \multirow{4}{*}{$\mathbf{I}$} & Repubblica & 61.9 & 0.3212 & 21.2 & 85 & 27.3 & 0.94 \\
\hline & Corriere della Sera & 61.9 & 0.3212 & 30 & 148 & 15.0 & 0.85 \\
\hline & linkiesta.it & 61.9 & 0.3212 & 83.3 & 13 & 54.2 & 0.86 \\
\hline & Lettera43 & 61.9 & 0.3212 & 51.7 & 16 & 72.4 & 0.86 \\
\hline \multirow{4}{*}{ USA } & NYTimes & 45.9 & 0.0291 & 80 & 1150 & 92.5 & 0.86 \\
\hline & LATimes & 45.9 & 0.0291 & 53.8 & 355 & 30.8 & 0.85 \\
\hline & Huffington Post & 45.9 & 0.0291 & 65 & 330 & 67.5 & 0.90 \\
\hline & Politico.com & 45.9 & 0.0291 & 37.5 & 145 & 55.0 & 0.89 \\
\hline
\end{tabular}


Table 3: Calibrated data on macro- and micro-levels (fuzzy-set values)

\begin{tabular}{|c|c|c|c|c|c|c|c|c|}
\hline $\begin{array}{l}\text { Count } \\
\text { ry }\end{array}$ & Site & $\begin{array}{l}\text { Country } \\
\text { with } \\
\text { economic } \\
\text { crisis }\end{array}$ & $\begin{array}{l}\text { High } \\
\text { intensity } \\
\text { of Occupy } \\
\text { protests }\end{array}$ & $\begin{array}{l}\text { Event- } \\
\text { driven } \\
\text { reportin } \\
\text { g } \\
\text { (solution } \\
\text { step 1) }\end{array}$ & $\begin{array}{l}\text { Extensive } \\
\text { Coverage } \\
\text { (High } \\
\text { amount of } \\
\text { articles with } \\
\text { more than } \\
500 \text { words) }\end{array}$ & $\begin{array}{l}\text { Big } \\
\text { newsroom } \\
\text { (High } \\
\text { numbers } \\
\text { of } \\
\text { journalist } \\
\text { s) }\end{array}$ & $\begin{array}{l}\text { Hyper- } \\
\text { textual } \\
\text { editing }\end{array}$ & $\begin{array}{l}\text { High } \\
\text { diversity } \\
\text { regardin: } \\
\text { topics an } \\
\text { actors }\end{array}$ \\
\hline \multirow{4}{*}{$\mathbf{C H}$} & NZZ & 0.2 & 0.45 & 0.45 & 0.01 & 0.69 & 0.57 & 0.05 \\
\hline & TA & 0.2 & 0.45 & 0.45 & 0.09 & 0.24 & 0.06 & 0.06 \\
\hline & Journal21 & 0.2 & 0.45 & 0.45 & 0.96 & 0.03 & 0.02 & 0.79 \\
\hline & news.ch & 0.2 & 0.45 & 0.45 & 0.85 & 0.06 & 0.02 & 0.00 \\
\hline \multirow{4}{*}{ D } & $\mathrm{SZ}$ & 0.4 & 0.55 & 0.55 & 0.80 & 0.07 & 0.98 & 0.75 \\
\hline & FAZ & 0.4 & 0.55 & 0.55 & 0.84 & 0.88 & 0.02 & 0.05 \\
\hline & SPON & 0.4 & 0.55 & 0.55 & 0.41 & 0.65 & 0.98 & 0.79 \\
\hline & Telepolis & 0.4 & 0.55 & 0.55 & 0.28 & 0.05 & 0.99 & 0.87 \\
\hline \multirow{4}{*}{$\mathbf{F}$} & Le Monde & 0.6 & 0.02 & 0.60 & 0.10 & 0.64 & 0.69 & 0.95 \\
\hline & Le Figaro & 0.6 & 0.02 & 0.60 & 0.11 & 0.82 & 0.25 & 0.17 \\
\hline & Rue89 & 0.6 & 0.02 & 0.60 & 0.77 & 0.05 & 0.98 & 0.99 \\
\hline & slate.fr & 0.6 & 0.02 & 0.60 & 0.62 & 0.05 & 0.99 & 0.98 \\
\hline \multirow{4}{*}{ UK } & Guardian & 0.4 & 0.07 & 0.40 & 0.97 & 0.99 & 0.32 & 0.68 \\
\hline & Times & 0.4 & 0.07 & 0.40 & 0.53 & 0.91 & 0.02 & 0.90 \\
\hline & Open Democracy & 0.4 & 0.07 & 0.40 & 0.99 & 0.06 & 0.97 & 0.93 \\
\hline & Telegraph & 0.4 & 0.07 & 0.40 & 0.48 & 0.96 & 0.07 & 0.01 \\
\hline \multirow{4}{*}{$\mathbf{I}$} & Repubblica & 0.8 & 0.96 & 0.96 & 0.05 & 0.45 & 0.15 & 1.00 \\
\hline & Corriere della & 0.8 & 0.96 & 0.96 & 0.15 & 0.60 & 0.07 & 0.26 \\
\hline & linkiesta.it & 0.8 & 0.96 & 0.96 & 0.96 & 0.04 & 0.60 & 0.55 \\
\hline & Lettera43 & 0.8 & 0.96 & 0.96 & 0.66 & 0.04 & 0.90 & 0.57 \\
\hline \multirow{4}{*}{ USA } & NYTimes & 0.6 & 0.51 & 0.60 & 0.95 & 1.00 & 0.99 & 0.55 \\
\hline & LATimes & 0.6 & 0.51 & 0.60 & 0.69 & 0.87 & 0.19 & 0.23 \\
\hline & Huffington Post & 0.6 & 0.51 & 0.60 & 0.85 & 0.85 & 0.86 & 0.97 \\
\hline & Politico.com & 0.6 & 0.51 & 0.60 & 0.31 & 0.60 & 0.62 & 0.93 \\
\hline
\end{tabular}


More of the Same or Marketplace of Opinions?

\section{Figures}

Figure 1: Conditions shaping diversity in news content

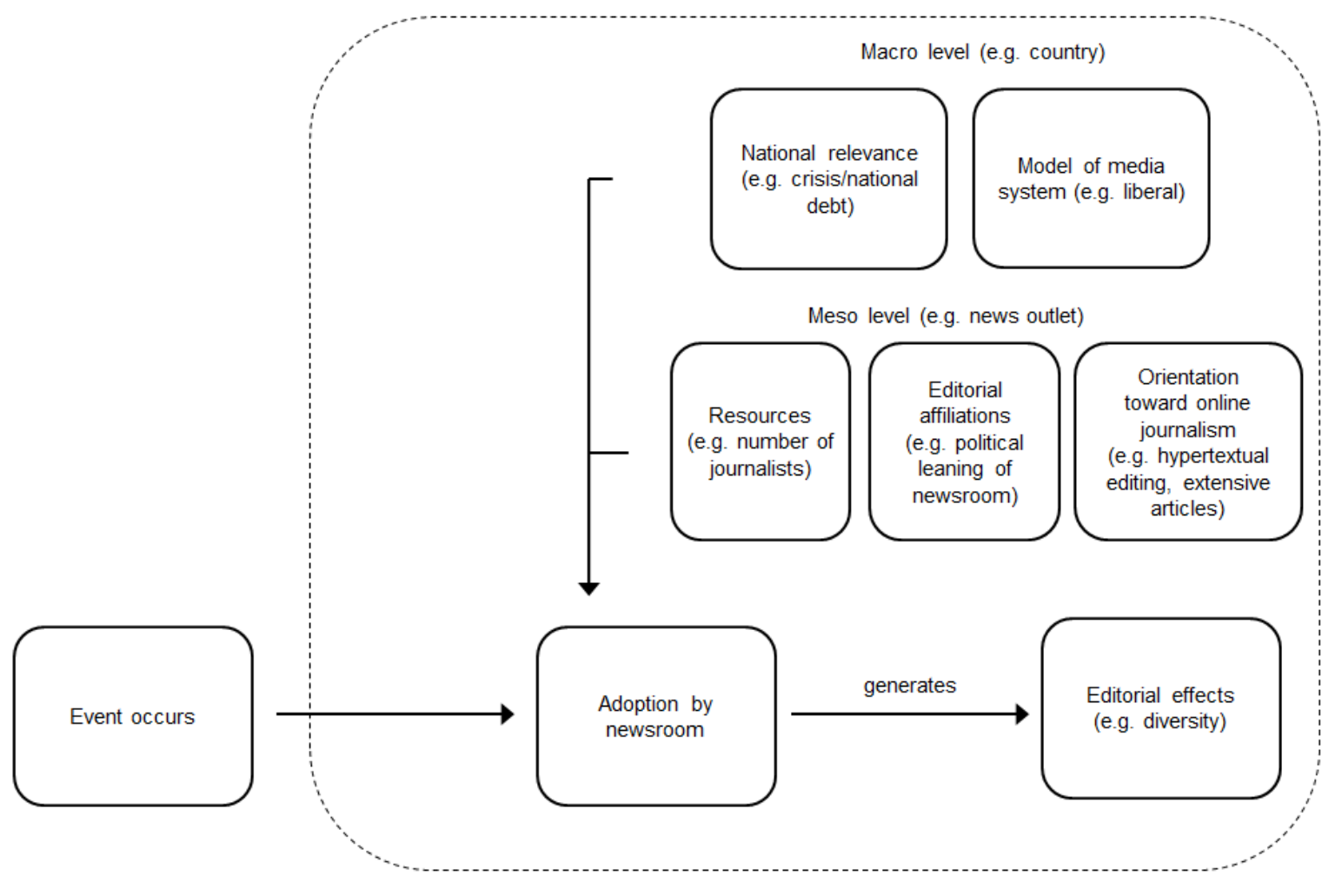


More of the Same or Marketplace of Opinions?

Figure 2: Outcome (diversity of topics and actors)

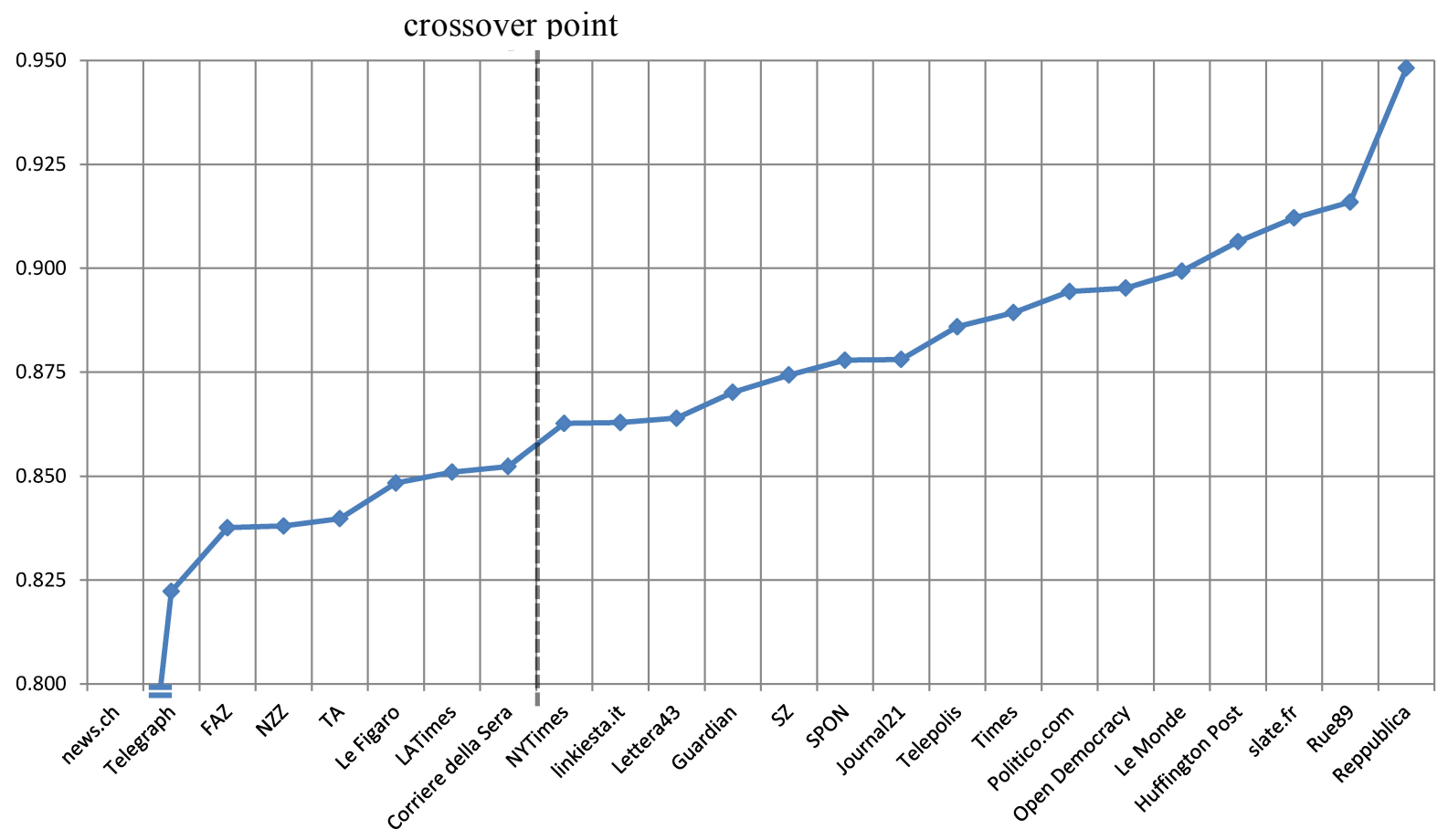


Figure 3: Solution plot and solution path for outcome high diversity
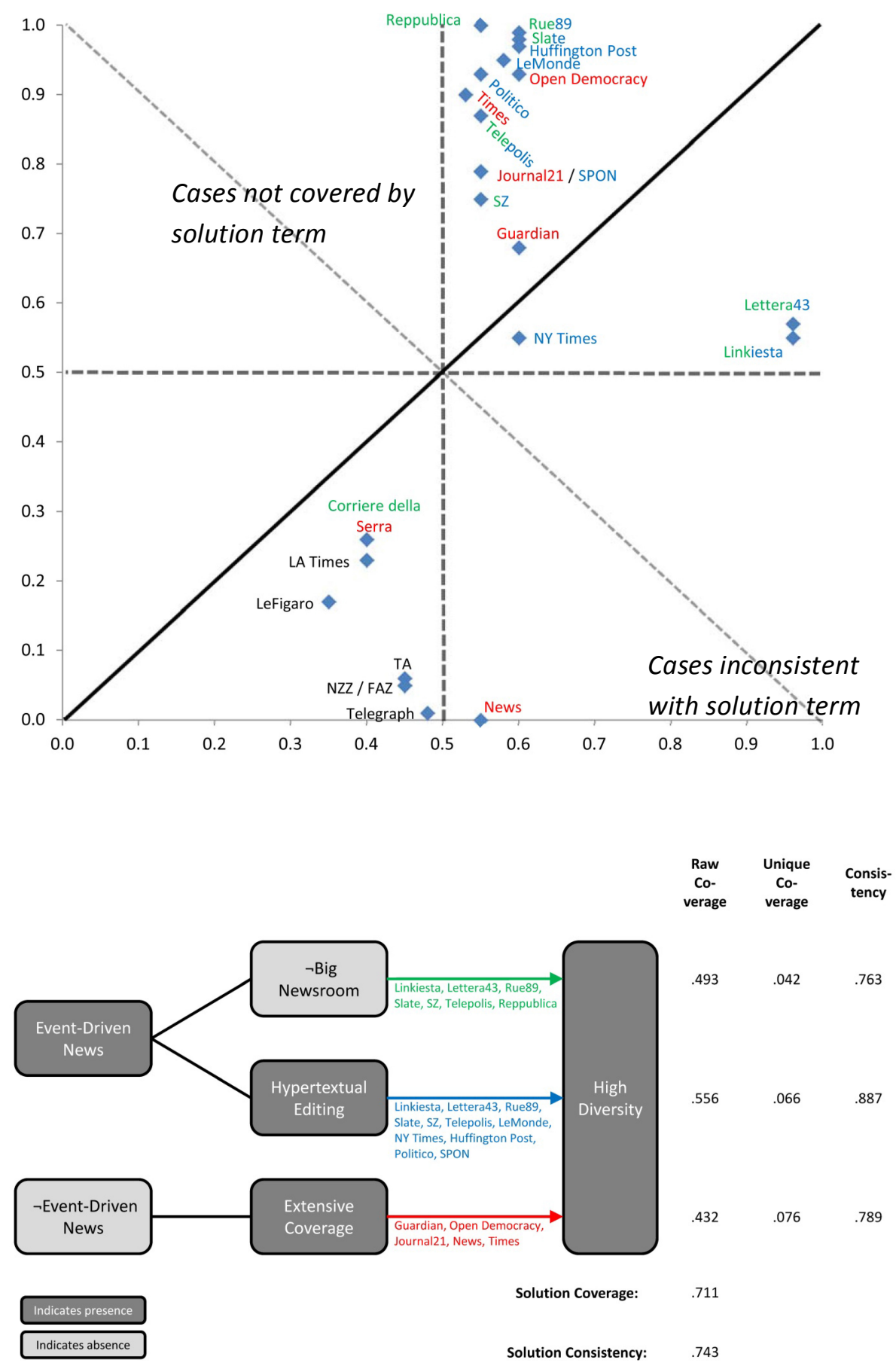
Figure 4: Solution plot and solution path for negated outcome
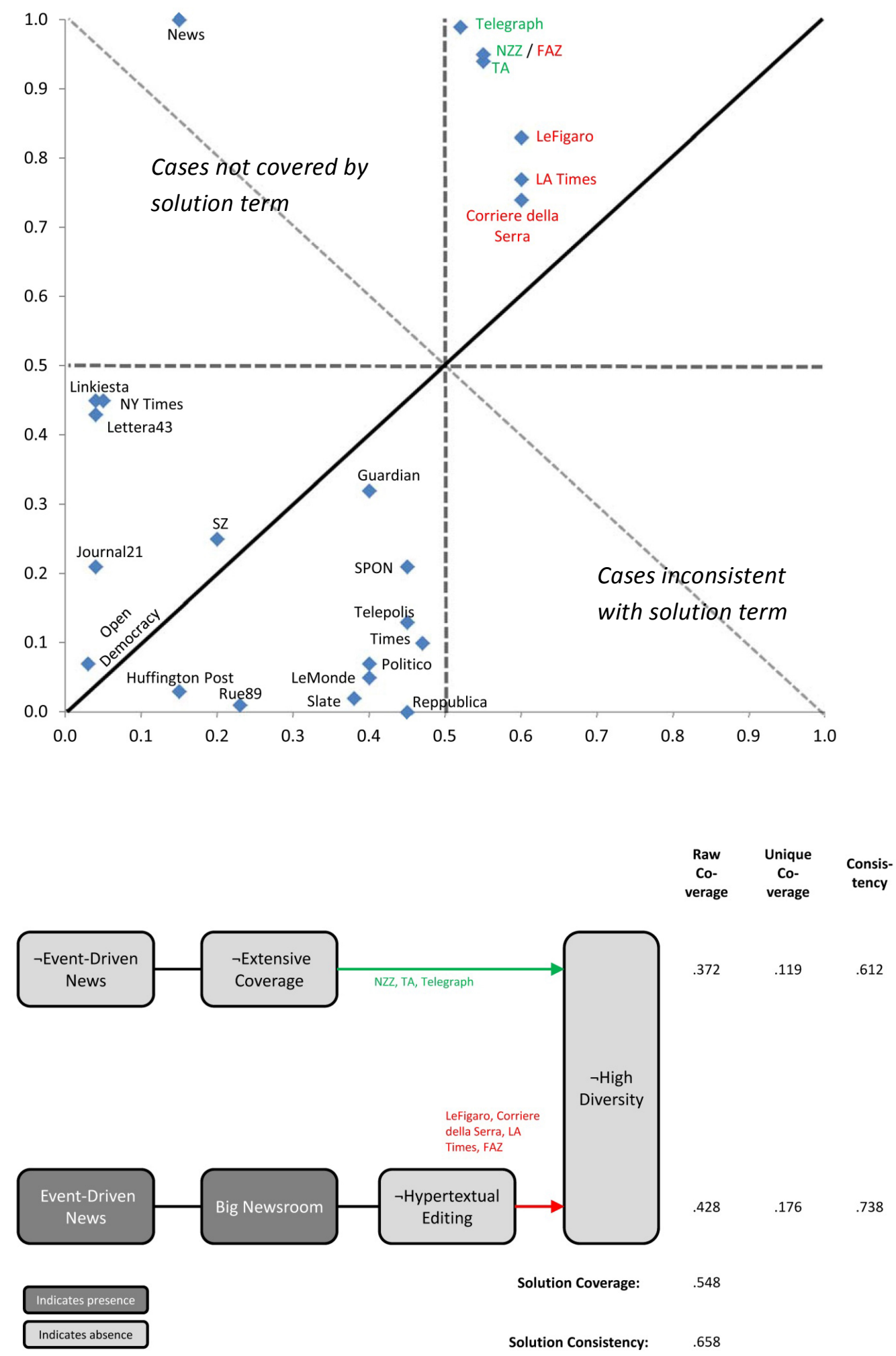


\section{Appendix}

A I: Topics coded in content analysis

\begin{tabular}{|c|c|c|c|c|c|c|}
\hline & $\mathrm{CH}$ & D & $\mathbf{F}$ & UK & I & USA \\
\hline General Politics & $1.4 \%$ & $1.1 \%$ & $1.1 \%$ & $1.6 \%$ & $4.3 \%$ & $4.1 \%$ \\
\hline Monetary Politics & $0.9 \%$ & $1.8 \%$ & $0.4 \%$ & $0.3 \%$ & - & $0.3 \%$ \\
\hline Tax Policies / Tax System & $0.5 \%$ & $0.4 \%$ & $0.7 \%$ & - & - & $0.3 \%$ \\
\hline Lobbying & $0.5 \%$ & - & $0.4 \%$ & $0.3 \%$ & $0.7 \%$ & - \\
\hline Social Welfare Policies & $1.9 \%$ & $0.7 \%$ & $1.8 \%$ & $0.5 \%$ & $0.7 \%$ & $1.9 \%$ \\
\hline National Debt & $1.4 \%$ & $1.4 \%$ & $0.7 \%$ & $0.3 \%$ & $0.7 \%$ & $0.8 \%$ \\
\hline Bank Rescue & - & $1.1 \%$ & - & - & - & $0.3 \%$ \\
\hline Others & - & $0.4 \%$ & $1.8 \%$ & $0.5 \%$ & $0.7 \%$ & - \\
\hline General Economics & - & $0.4 \%$ & $0.4 \%$ & - & $1.0 \%$ & $1.7 \%$ \\
\hline Crisis of the Economy & - & $7.4 \%$ & $2.1 \%$ & $3.5 \%$ & $1.3 \%$ & $1.7 \%$ \\
\hline Banks & $2.8 \%$ & $2.1 \%$ & $1.8 \%$ & $0.5 \%$ & $2.0 \%$ & $0.6 \%$ \\
\hline Taxes & - & $0.4 \%$ & $0.4 \%$ & - & - & - \\
\hline General Property & $0.9 \%$ & $0.4 \%$ & - & - & $0.3 \%$ & $0.8 \%$ \\
\hline Wall Street / Financial Industry & $2.3 \%$ & $3.5 \%$ & $5.3 \%$ & $1.1 \%$ & $0.7 \%$ & $0.8 \%$ \\
\hline Labour Market & - & $0.7 \%$ & $1.4 \%$ & $0.3 \%$ & $0.3 \%$ & $0.6 \%$ \\
\hline Others & - & $0.4 \%$ & - & $1.1 \%$ & - & - \\
\hline Occupy Wall Street (OWS) / Activism & $1.4 \%$ & $1.8 \%$ & $2.8 \%$ & $2.9 \%$ & $5.0 \%$ & $7.5 \%$ \\
\hline OWS Media Resonance & $1.9 \%$ & $2.5 \%$ & $2.5 \%$ & $2.7 \%$ & $2.7 \%$ & $5.0 \%$ \\
\hline OWS Demonstration / Strike & $31.9 \%$ & $29.1 \%$ & $22.4 \%$ & $26.3 \%$ & $23.6 \%$ & $21.8 \%$ \\
\hline OWS Activists & $5.1 \%$ & $3.9 \%$ & $6.8 \%$ & $12.9 \%$ & $12.3 \%$ & $6.6 \%$ \\
\hline OWS Demands & $6.9 \%$ & $8.5 \%$ & $5.7 \%$ & $5.1 \%$ & $4.0 \%$ & $4.1 \%$ \\
\hline Solidarity by OWS & $0.5 \%$ & - & $1.1 \%$ & $1.1 \%$ & $1.0 \%$ & $1.7 \%$ \\
\hline Solidarity for OWS & $5.6 \%$ & $5.0 \%$ & $6.0 \%$ & $8.0 \%$ & $5.6 \%$ & $6.9 \%$ \\
\hline OWS-Media (own / Social Media) & $0.9 \%$ & $1.8 \%$ & $1.8 \%$ & $1.6 \%$ & $2.7 \%$ & $1.9 \%$ \\
\hline Infiltration of OWS & $0.9 \%$ & $1.8 \%$ & $1.4 \%$ & $0.8 \%$ & $2.3 \%$ & $0.8 \%$ \\
\hline Arab Spring Revolts & - & - & $1.4 \%$ & $1.3 \%$ & $0.3 \%$ & $1.4 \%$ \\
\hline General Social Dissatisfaction & $2.8 \%$ & $0.4 \%$ & $2.5 \%$ & $2.9 \%$ & $5.3 \%$ & $1.4 \%$ \\
\hline Class Society / Power Structures & $2.3 \%$ & $1.8 \%$ & $3.2 \%$ & $1.3 \%$ & $1.7 \%$ & $2.8 \%$ \\
\hline Capitalism / Profit / Growth & $2.8 \%$ & $1.4 \%$ & $1.8 \%$ & $1.6 \%$ & $1.0 \%$ & $0.6 \%$ \\
\hline State-run Repression & $12.5 \%$ & $5.3 \%$ & $6.8 \%$ & $6.4 \%$ & $5.3 \%$ & $8.8 \%$ \\
\hline Militant Activists & $3.7 \%$ & $3.9 \%$ & $4.3 \%$ & $3.8 \%$ & $2.3 \%$ & $2.5 \%$ \\
\hline Others & $0.5 \%$ & $1.4 \%$ & $1.1 \%$ & $1.1 \%$ & $1.7 \%$ & $0.6 \%$ \\
\hline Comments, Perspectives, Opinions & $0.9 \%$ & $0.4 \%$ & $1.1 \%$ & $0.5 \%$ & $0.7 \%$ & $0.3 \%$ \\
\hline By Media about OWS & $0.9 \%$ & $3.9 \%$ & $1.4 \%$ & $3.2 \%$ & $4.3 \%$ & $4.7 \%$ \\
\hline By Politics about OWS & $3.7 \%$ & $1.8 \%$ & $3.9 \%$ & $1.3 \%$ & $2.7 \%$ & $3.3 \%$ \\
\hline By Economy about OWS & $0.5 \%$ & $0.7 \%$ & $1.1 \%$ & $0.3 \%$ & $1.3 \%$ & $0.3 \%$ \\
\hline By OWS / Activists about Others & $1.9 \%$ & $2.8 \%$ & $2.8 \%$ & $1.3 \%$ & $1.7 \%$ & $0.6 \%$ \\
\hline
\end{tabular}




\begin{tabular}{|c|c|c|c|c|c|c|}
\hline & $\mathbf{C H}$ & D & $\mathbf{F}$ & UK & I & USA \\
\hline General Political Actors & - & $3.23 \%$ & $0.69 \%$ & $3.80 \%$ & $4.63 \%$ & $2.11 \%$ \\
\hline Executive & $9.50 \%$ & $5.38 \%$ & $10.69 \%$ & $5.98 \%$ & $7.47 \%$ & $10.79 \%$ \\
\hline Legislative & $0.45 \%$ & $1.08 \%$ & $0.00 \%$ & $1.09 \%$ & $0.71 \%$ & $0.79 \%$ \\
\hline Judicative & - & $0.36 \%$ & $1.03 \%$ & $0.82 \%$ & $1.42 \%$ & $2.11 \%$ \\
\hline State Authorities & $18.55 \%$ & $11.47 \%$ & $9.66 \%$ & $14.67 \%$ & $10.32 \%$ & $13.16 \%$ \\
\hline Parties & $6.33 \%$ & $3.23 \%$ & $4.48 \%$ & $1.90 \%$ & $0.36 \%$ & $3.16 \%$ \\
\hline Others & - & $0.72 \%$ & $1.72 \%$ & $0.54 \%$ & - & $0.79 \%$ \\
\hline General Economic Actors & - & $0.72 \%$ & $0.69 \%$ & $1.09 \%$ & $0.71 \%$ & $1.32 \%$ \\
\hline Financial Industry & $1.81 \%$ & $3.58 \%$ & $1.72 \%$ & $2.17 \%$ & $1.78 \%$ & $0.53 \%$ \\
\hline Banks & $2.71 \%$ & $5.02 \%$ & $2.41 \%$ & $0.54 \%$ & $3.20 \%$ & $0.53 \%$ \\
\hline Real Economy & $0.45 \%$ & - & - & - & - & - \\
\hline Central Banks & - & $0.72 \%$ & $0.34 \%$ & - & - & - \\
\hline Economic Lobbying Organizations & - & - & - & - & $2.14 \%$ & $1.05 \%$ \\
\hline Multinational Concerns (Explicitly) & $0.45 \%$ & $1.08 \%$ & - & - & $0.36 \%$ & - \\
\hline Others & $0.45 \%$ & - & $0.69 \%$ & $1.09 \%$ & - & $0.26 \%$ \\
\hline General Civil Societal Actors & $0.45 \%$ & $1.43 \%$ & $1.03 \%$ & $1.36 \%$ & $3.56 \%$ & $4.21 \%$ \\
\hline Trade Unions & $0.45 \%$ & - & $0.69 \%$ & $0.27 \%$ & $1.07 \%$ & $1.05 \%$ \\
\hline NGOs, NPOs, etc. & $0.45 \%$ & $2.51 \%$ & - & $0.27 \%$ & $0.36 \%$ & - \\
\hline Associations & - & $1.08 \%$ & - & $0.54 \%$ & - & $1.32 \%$ \\
\hline Non-Economic Lobbying Actors & $0.45 \%$ & $0.36 \%$ & - & $0.27 \%$ & $0.36 \%$ & $0.26 \%$ \\
\hline OWS / "99\%" & $40.27 \%$ & $35.48 \%$ & $34.14 \%$ & $35.33 \%$ & $34.16 \%$ & $36.58 \%$ \\
\hline Rich / "1\%" & $0.90 \%$ & $1.79 \%$ & $5.17 \%$ & $0.82 \%$ & $2.49 \%$ & $0.53 \%$ \\
\hline Further Activists & $1.81 \%$ & $5.38 \%$ & $2.07 \%$ & $5.16 \%$ & $5.69 \%$ & $3.95 \%$ \\
\hline Others & - & $1.43 \%$ & $2.07 \%$ & $2.72 \%$ & - & $2.89 \%$ \\
\hline General Scientific Actors & - & - & - & - & $0.36 \%$ & - \\
\hline Scientist & $4.07 \%$ & $1.43 \%$ & $2.76 \%$ & $0.27 \%$ & $1.78 \%$ & $0.26 \%$ \\
\hline University & $0.45 \%$ & - & $0.34 \%$ & - & $1.07 \%$ & $0.26 \%$ \\
\hline Students & - & $0.36 \%$ & $3.10 \%$ & $0.27 \%$ & $1.78 \%$ & $0.79 \%$ \\
\hline Others & - & $0.36 \%$ & $0.34 \%$ & $0.54 \%$ & $1.07 \%$ & - \\
\hline General Media Actors & $0.45 \%$ & $1.43 \%$ & $2.07 \%$ & $1.90 \%$ & $1.07 \%$ & $1.84 \%$ \\
\hline TV & - & $0.72 \%$ & $0.34 \%$ & $0.54 \%$ & - & $0.26 \%$ \\
\hline Internet & - & $0.72 \%$ & $1.38 \%$ & $0.82 \%$ & $1.42 \%$ & $0.79 \%$ \\
\hline Print & $0.45 \%$ & $1.08 \%$ & $0.34 \%$ & $0.27 \%$ & $0.71 \%$ & $0.53 \%$ \\
\hline Social Media & - & $0.36 \%$ & $2.07 \%$ & $1.09 \%$ & $2.14 \%$ & $0.79 \%$ \\
\hline Journalists & $0.90 \%$ & $1.08 \%$ & $1.72 \%$ & $0.54 \%$ & $1.42 \%$ & $1.84 \%$ \\
\hline Others & - & - & $0.69 \%$ & $0.54 \%$ & $0.71 \%$ & $0.53 \%$ \\
\hline General Religious Actors & - & - & - & - & - & $0.26 \%$ \\
\hline Churches & $3.17 \%$ & $1.08 \%$ & $1.38 \%$ & $3.80 \%$ & $1.78 \%$ & $0.26 \%$ \\
\hline Clergy & $1.36 \%$ & $0.72 \%$ & $2.07 \%$ & $4.89 \%$ & - & - \\
\hline Believer & $0.45 \%$ & - & - & $0.27 \%$ & - & $0.53 \%$ \\
\hline General Prominence Actors & $0.45 \%$ & $0.72 \%$ & $0.34 \%$ & - & $0.71 \%$ & - \\
\hline Showbiz & $0.45 \%$ & $1.08 \%$ & $1.72 \%$ & $1.63 \%$ & $1.07 \%$ & $1.32 \%$ \\
\hline Sports & - & - & - & $1.36 \%$ & - & $0.26 \%$ \\
\hline Others & $2.26 \%$ & $2.87 \%$ & - & $0.54 \%$ & $1.42 \%$ & $1.32 \%$ \\
\hline Other Actors & - & - & - & $0.27 \%$ & $0.71 \%$ & $0.53 \%$ \\
\hline
\end{tabular}

